\title{
State-wise Malnutrition Analysis in India: Findings from NFHS III
}

\author{
Ashima Gupta \\ Research Scholar, IGNOU, Delhi, India
}

\begin{abstract}
A healthy, balanced diet is vital for maintaining health and fitness. A country with physically and mentally fit people can attain overall development much faster than the country with malnourished and weak people. The malnutrition may be caused by low dietary intake, infectious diseases, lack of appropriate care, and inequitable distribution of food within the household. The malnutrition experienced by children is difficult to readdress beyond a certain break-point since most of the development deficits and damages caused within the first two years of life are irreversible. This paper attempts to bring out the effect of wealth quintile and family size on children under five years of age among the major states of India by analysing the data from NFHS III.
\end{abstract}

Keywords: Malnutrition, Stunted, Wasted, Underweight, Wealth Quintile.

\section{Introduction}

Malnutrition is simply the lack of proper nutrition which could be caused by not having enough to eat or not eating enough of the right things or being not able to utilise the food that a person eats. This is to say that even if the people have enough food to eat, they can still be malnourished because of the insufficient amount of micronutrientsvitamins and minerals present in the food to meet the daily nutritional requirements and are unable to do normal things like growing and resisting diseases, physical work and like. In certain cases, even the learning abilities might get diminished.

NFHS III describes the nutritional status of children under 5 years of age by taking three standard indices of physical growth: stunting, wasting and underweight. Stunted is an indicator of linear growth retardation and cumulative growth deficits and represents the long-term effects of malnutrition in a population and does not vary according to recent dietary intake. Wasting measures body mass in relation to body length and describes current nutritional status. The possible causes may be inadequate food intake or a recent episode of illness causing loss of weight and the onset of malnutrition. Underweight is a composite index of height-for-age and weight-for-height. It takes into account both acute and chronic malnutrition.

\section{Objective}

The objective of this paper is to find the concentration of malnutrition by wealth quintiles and family size among children of under 5 age group in the major states of India.

\section{Methodology}

State - wise analysis of NFHS III data base is being done here. Unit data on child size and household size is used. The total sample size taken in NFHS III survey is 46655. The age group for children is 0 to 5 years. Here an attempt is made to compile the data on three indices of malnourishment for the State level by taking the major states only. The stunted, wasted and underweight are compiled in the light of two variables i.e. wealth quintiles and family size. The wealth quintiles are divided into five categories, the first is the lowest and the last being the highest. The family size is divided into five categories i.e. households having family size below 3, 3 to 4, 4 to 5, 5 to 6 and 7 or greater than 7 . In calculating the state figures only the total population is taken rather than segregating into rural and urban classification because of the inadequacy of the urban sample.

Nutritional indicators are expressed in standard deviation units (Z-scores) from the median of the reference population. Children whose Z-score for height-for-age index, Weight-for-height index and Weight-for-age index are below minus two standard deviations ( -2 SD) from the median of the reference population are considered to be stunted, wasting and underweight respectively.

\section{Hypothesis}

Malnutrition among children with low income and big family sizes is far more than their counterparts in high income group and small family size.

\section{Literature Review}

The poor negative performance in human development indicators has a significant implication for the situation of children (0 to 17 years) in India which represent $37 \%$ of the total population in 2011 (Census of India 2011).

According to 2011 OECD report, income inequality has doubled in India since the early 1990s (OECD, 2011). As per the NSS 2011-12 survey, more than a quarter of total Indian rural households are poor and about $83 \%$ are in the poorest quintile, which is twice as many as in the highest one.

"Infant and young child feeding practices in particular continue to be a serious challenge to reduce malnutrition among children. In spite of unprecedented economic growth, improvements in childhood nutritional status in India over the last decade have been slow. The status of various aspects of nutrition among children points towards urgent need to take the call for aggressive awareness campaigns along with improved health care facilities with special privileges for the weaker sections of the society" (GOI, 2012). 


\section{International Journal of Science and Research (IJSR) \\ ISSN (Online): 2319-7064}

Index Copernicus Value (2013): 6.14 | Impact Factor (2015): 6.391

\section{Analysis}

The following bar graph depicts the percentage of stunted, wasted and underweight children in India. Rural and urban figures are depicted separately.

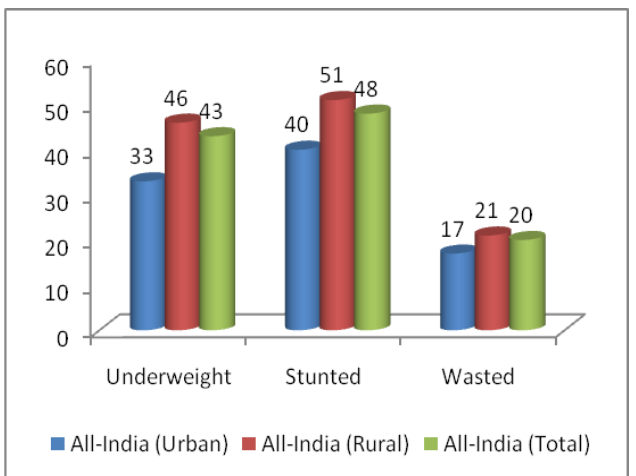

\section{Source: NFHS III}

Rural India has high incidence of underweight, stunted and wasted children as compared to urban sates of India. In India the total percentage of children stunted, wasted and underweight are 48.3, 42.8 and 20.1 per cent respectively.

The NFHS III data analysis shows that Bihar (48.7), Chhattisgarh (54.2), Madhya Pradesh (50.0) are the states where there is a highest percentage of stunted children while Kerala (24.7) has the lowest. If we categorise these states according to the wealth quintile, then the lowest and the second lowest category shows the maximum stunting while the highest wealth quintile shows the least stunting among under 5 children. Chhattisgarh with respect to wealth quintiles of lowest to highest category shows the stunting of $58,60,50,50$ and 20 percent respectively. The trend is the same in all the poor states. The percentage of stunted children in Kerala is 46 percent in the lowest wealth quintile in comparison to only 19 percent in the highest wealth quintile. Chhattisgarh shows only a negligible 1 percent stunted children in the family size of less than 3 people while 58 percent among the 7 or more people family size. The similar trend is seen in all the other states as well.

Looking at the states for percentage of children who are wasted, the states which show the highest percentage are Madhya Pradesh, Jharkhand and Bihar with 35.7, 33.1, 27.6 respectively. This represents the failure among children to receive adequate nutrition in the period immediately preceding the survey and may be the result of inadequate food intake or a recent episode of illness causing loss of weight and the onset of malnutrition. The percent of wasted children is high in lowest wealth quintile and large family sizes in all the states. In Bihar the percent of wasted children in the lowest wealth category is double of that in the highest category. In the state of Punjab where the percentage of wasted children is the least (9.1), the wasted children in lowest category are three times that of the highest category. There is a complete absence of wasting among the small family size with less than 3 people for all the major states in India while as the family size grows, there is a high incidence of wasting.
The percentage of underweight children in Madhya Pradesh is 60.2, Jharkhand is 57.4 and in Bihar is 56.6 which is highest among all the states in India. This takes into account both acute and chronic malnutrition. Kerala (23.0) has the least percentage of underweight children. However, as in the case of stunting and wasting, the percentage of underweight children is far more in lowest wealth quintile category as compared to the highest wealth category. Also, there are almost nil cases of underweight children in small families with less than 3 people while the percentage soars as we move up the family size.

A majority of stunted, wasted and underweight children belongs to the households having a high family size and low income. It goes without saying that with a handful of food and limited monetary income, families with more children are bound to have more nutrition deficiency than with households with fewer children. Additionally hungry mouths can't be fed with the same amount of food. People, particularly living in rural areas, think of more children as more earning hands. The fact is, however, that these children must be properly raised and sufficiently fed before they turn into an economic support for the family.

\section{Conclusion}

A state-wise analysis of malnutrition shows that malnutrition among children in low wealth quintile category and big family sizes is far more than their counterparts in high wealth group and small family size.

\section{References}

[1] Mishra, S. K and Rajni Menon (2012) "Child Health Deprivation in India: A Study Based on NFHS Outcome Indicators", paper presented in the National seminar on ,Social Exclusion in Contemporary India ${ }^{\text {ee }}$ at Institute of Development Studies, Jaipur.

[2] Rustagi, P, S.K. Mishra and B. S. Mehta (2011) "Scheduled Tribe Children in India: Multiple Deprivations and Locational Disadvantage", IHDUNICEF Working Paper Series on 'Children of India: Rights and Opportunities' UNICEF and Institute for Human Development.

[3] Ministry of statistics and Programme Implementation Government of India (2012)- "Children in India - A Statistical Appraisal"

[4] Gaspar Farjth and Katherine Holland (2007), "Poverty and Children: A Perspective." UNICEF DPP Working Paper, 2007 OECD (2011), „Inequality in Emerging Economies $^{\text {ee }}$ OECD, Downloaded from http://www.oecd.org/els/soc/49170475.pdf

[5] Jonathan Bradshaw, Petra Hoelscher and Dominic Richardson, "Comparing child well-being in OECD countries: Concepts and methods", IWP 2006-03, Innocenti Research Centre.

[6] Alkire Sabina (2011), „The Capability Approach and Human Development ${ }^{\text {e }}$ OPHI, Working paper no. 46. 